\title{
Final Year Dental Students' Perception of Knowledge, Training and Competence in Medical Emergency Management
}

\author{
Liqaa Abdulridha Raffee ${ }^{1}$, Yousef S Khader ${ }^{2}$, Alaa O. Oteir ${ }^{3}$, Khaled Z. Alawneh ${ }^{4}$, Rola S. Saqan ${ }^{5}$, \\ Bronwyn Beovich $^{6} \&$ Brett Williams $^{6}$ \\ ${ }^{1}$ Faculty of Medicine, Department of Accident and Emergency Medicine at Jordan University of Science and \\ Technology (JUST), Irbid, Jordan \\ ${ }^{2}$ Epidemiology and Biostatistics, JUST, Irbid, Jordan \\ ${ }^{3}$ Paramedic Program, JUST, Irbid, Jordan \\ ${ }^{4}$ Radiology Department, JUST, Irbid, Jordan \\ ${ }^{5}$ King Abdullah University Hospital, Irbid, Jordan \\ ${ }^{6}$ Department of Community Emergency Health and Paramedic Practice, Monash University, Frankston, Australia \\ Correspondence: Liqaa Abdulridha Raffee, Faculty of Medicine, Department of Accident and Emergency \\ Medicine at Jordan University of Science and Technology (JUST), Irbid, Jordan. Tel: 962-79-531-3555. E-mail: \\ laraffee5@just.edu.jo
}

Received: January 27, 2018 Accepted: February 20, 2018 Online Published: April 23, 2018

doi:10.5539/gjhs.v10n6p1

URL: https://doi.org/10.5539/gjhs.v10n6p1

\begin{abstract}
Objective: The potential for a medical emergency to occur during dental treatment must be met by dental practitioners who are competent to manage such situations. However the literature shows that not all dentists have received training in this area, and of those who have, many are deficient in knowledge, skills and confidence. The objective of this study was to examine the perceptions of final year Jordanian dental students regarding their education and preparedness to manage medical emergencies.
\end{abstract}

Methods: This study was a cross-sectional, descriptive study which gathered questionnaire data from an undergraduate student cohort at two Jordanian universities. Descriptive analysis of the data was undertaken, and a Chi-squared test was used to explore the relationships between participants' responses and the variables of gender and previous attendance at any ME workshop. Statistical significance was deemed at $\mathrm{p}<.05$.

Results: Three hundred and seventy dental students responded to the questionnaire with response rates of $76.2 \%$ and $81.8 \%$ from the two sites. The results indicate that not all of the students had received training in medical emergency management, and their self-reported proficiency and experience was sub-optimal. However, participating in a workshop on managing medical emergencies was associated with changes in some skills and experiences.

Conclusion: The low levels of medical emergency management knowledge and skills in the final year dental students reflects the situation reported in existing literature. This study indicates the importance of effective medical emergency management training within the dental undergraduate program, and may be used to inform future curricula planning.

Keywords: cardiopulmonary resuscitation, dental education, emergency treatment, curriculum

\section{Introduction}

As the global population continues to age, both the proportion and absolute number of older people are increasing (World Health Organization, 2015). To illustrate this, it has been estimated that the population over 65 years of age in the United States of America (US) will more than double in the years between 2005 and 2050 (Passel \& Cohn, 2008). Likewise, the population of all countries of the Middle East is projected to increase dramatically over future decades, including Jordan which has a projected increase of 70\% between 2007 and 2050 (Roudi-Fahimi \& Kent, 2007). With increasing age, there is an increasing incidence of chronic diseases such as cardiovascular, respiratory, musculoskeletal, mental and neurological disorders, as well as cancer, diabetes, and dementia (Prince et al., 2015). It has been estimated that $80 \%$ of elderly people have one chronic disease and $50 \%$ have two or more (National 
Centre for Chronic Disease Prevention and Health Promotion, 2011).

This worldwide change in demographic profile of the population increases the likelihood that dental patients will present with more complex medical histories, thereby increasing the potential for medical problems to occur during dental care (Little, Miller, \& Rhodus, 2018). A study from the US reported that patients in their dental clinic had an average age of 52 years, and over half were taking medication or had at least one systemic illness (Radfar \& Suresh, 2007). The combination of an aging patient profile, multi-morbidity and medications taken results in an increasingly medically complex patient cohort, thereby necessitating that dentists are prepared to identify and manage medical emergencies (MEs). Furthermore, dental procedures such as anaesthesia or surgery may increase the possibility of a ME occurring in predisposed patients (Laurent et al., 2009).

MEs may occur at any time, in any environment, including within a dental practice, and have been reported to be over 5 times more likely to occur in a dental office than a medical office (Feck, 2012). The incidence of MEs has been reported at 164 events per million dental visits (Anders, Comeau, Hatton, \& Neiders, 2010). An earlier report concluded that a dentist who practices for 40 years will be exposed to between nine and eleven emergency events throughout their career (Atherton et al., 1999), and studies from various countries have reported that 32 to $69 \%$ of dentists have encountered a ME in their practice (Čuković - Bagić et al., 2017; Müller, Hänsel, Stehr, Weber, \& Koch, 2008; Mwita, Machibya, \& Nyerembe, 2017). Although it is difficult to compare frequency levels due to various timeframes being used for data collection, this does indicate that MEs do occur and are an important consideration in dental practice.

Vasovagal syncope is often cited as the most commonly occurring ME in dental practice (Alhamad et al., 2015; Müller et al., 2008). However other MEs that may occur include: cardiac arrest, anaphylaxis, airway obstruction, stroke, as well as hypoglycaemic, asthmatic, and epileptic episodes (Leelavathi, Reddy, Elizabeth, \& Priyadarshni, 2016; Müller et al., 2008). While the occurrence of a ME is relatively infrequent in dental practice, all dentists have a duty of care to provide effective and safe care to their patients (Jevon, 2012). This imperative includes the ability to identify and manage a ME should one arise. A slow or non-existent response to a ME such as a cardiac arrest may worsen a patient's prognosis considerably (Resuscitation Council (UK), 2015).

However, previous research indicates that dentists may lack the knowledge, confidence and preparedness to be able to manage MEs that may occur within their practice (Alhamad et al., 2015; Arsati et al., 2010; Broadbent \& Thomson, 2001). The literature suggests that not all dentists are exposed to training about MEs, or basic life support (BLS) including cardiopulmonary resuscitation (CPR) (Leelavathi et al., 2016; Müller et al., 2008; Stafuzza, Carrara, Oliveira, Santos, \& Oliveira, 2014). For example, a study carried out in New Zealand reported that $18 \%$ of dentists had no undergraduate ME training (Broadbent \& Thomson, 2001), and approximately $25 \%$ of two different cohorts in India reported no ME training (Abraham \& Afradh, 2016; Varma, Pratap, Padma, Kalyan, \& Vineela, 2015). However even for those dental practitioners who have received training about MEs or BLS, many do not feel confident or competent to deliver these skills effectively (Stafuzza et al., 2014; Varma et al., 2015). Moreover, basic and advanced life support skills have been shown to deteriorate after only 6 months post skill acquisition (Cooper, Johnston, \& Priscott, 2007; Yang et al., 2012), highlighting the importance of ongoing, recurrent training or refresher courses, both at undergraduate and postgraduate levels.

The dental program at the Jordan University of Science and Technology (JUST) is a five year undergraduate program, where second year students have a one-hour theoretical session covering basic emergency care taught by an emergency physician. This is a newly introduced course started two years ago, at the commencement of this study. The dental program at the University of Jordan (JU) is also a five year program which includes a three hour theoretical session covering the principles of first-aid, and also taught to second year students. The aim of the study was to examine perceptions of final year dental students at JUST and JU regarding their education and preparedness to manage MEs within a dental office.

\section{Methods}

This study was approved by the JUST Institutional Research Board (IRB protocol number 182/2015). Student responses were examined using a cross-sectional, descriptive methodology. A paper-based questionnaire developed by the authors at JUST was used to gather demographic information as well as information regarding participants' self-perceived skills and competencies of managing MEs, the types of MEs and emergency procedures they had encountered, and whether they had attended any ME training.

The questionnaire had not been previously utilised, and as such the reliability and validity was yet to be determined. In this study, it was used in an exploratory capacity to gather data on a topic in a previously unexamined cohort. Further studies will be required to determine the aforementioned questionnaire characteristics. The questions were 
selected via author consultation and consensus. Initially, the questionnaire was distributed to a group of ten JUST dental students as a pilot study to evaluate their understanding of the questions. After student feedback, amendments were made to the questionnaire. The ten students who participated in the pilot study were excluded from the subsequent study group. The finalised survey was distributed to students from both participating universities by research assistants and the principle investigator at the conclusion of lectures and was collected after survey completion. Participation was voluntary, and consent was implied by return of a completed survey.

Data analysis was completed with the Statistics Package for the Social Sciences (IBM SPSS v17). Descriptive analysis of the data was undertaken, and a Chi-squared test for independence (with Yates Continuity Correction) was used to explore the relationships between participants' responses and the variables of gender and previous attendance at any ME workshop. Statistical significance was deemed at $\mathrm{p}<.05$.

\section{Results}

A total of 370 dental students responded to the questionnaire with a response rate from JUST of $76.2 \%(253 / 332)$ and $81.8 \%(117 / 143)$ from JU. The majority $(66.2 \%)$ were female and the mean age was 22.9 (SD 1.3) years. Most (68.4\%) were enrolled at the Jordan University of Science and Technology (JUST) and 31.6\% at the University of Jordan (JU).

Approximately half of the respondents (51.6\%) reported receiving CPR training, and $42.7 \%$ had attended a workshop on managing MEs. Although $91.9 \%$ of respondents reported that they had knowledge about CPR, only $51.4 \%$ reported that they could perform CPR. Self-perceived competency with regards to emergency treatment and drugs revealed that $75.7 \%$ had knowledge about oxygen and its route of administration, and $69.5 \%$ reported the same knowledge of adrenaline. Almost eight in ten students (79.5\%) were aware of common drugs used in dentistry that may precipitate an allergic reaction.

The self-reported proficiency in various ME management skills was generally low. For example, less than $50 \%$ of respondents felt they possessed skills in administering artificial respiration or the Heimlich manoeuvre. Proficiency in giving injections by various routes was also low $(23.2 \%-45.8 \%)$, however more than eight in ten individuals felt they were able to check the carotid pulse (Table 1).

Table 1. Self-perceived possession of ME management skills

\begin{tabular}{ll}
\hline Do you have the following skills? & Yes \\
\hline Artificial respiration $(\mathrm{n}=370)$ & $\mathrm{n}(\%)$ \\
Give an IM injection $(\mathrm{n}=369)$ & $160(43.2)$ \\
Give a S/C injection $(\mathrm{n}=370)$ & $169(45.8)$ \\
Give an IV injection $(\mathrm{n}=370)$ & $120(32.4)$ \\
Check the carotid pulse $(\mathrm{n}=370)$ & $86(23.2)$ \\
Perform Heimlich manoeuvre $(\mathrm{n}=370)$ & $306(82.7)$ \\
\hline
\end{tabular}

The proportion of the students who had previously encountered various MEs ranged from $24.9 \%-37.3 \%$ and the proportion that had encountered the specified ME procedures ranged from $10 \%-15.7 \%$ (Table 2). Approximately four in ten students $(42.7 \%$ ) had attended a workshop on managing MEs, however overall $83.5 \%$ said that they were willing to attend any ME training in the future. For those that had not attended a ME workshop, their reasons for non-attendance were as follows: lack of time $24.3 \%$, not interested $26.5 \%$, didn't know where to go $36.2 \%$, and felt it was unnecessary for a dentist $12.7 \%$. For those that had attended ME training, all four included training modalities; simulation, seminars, videotapes, and slides / PowerPoint, were reported to have been used (Table 2). 
Table 2. Medical Emergency training and experiences

\begin{tabular}{|c|c|c|}
\hline Variable & & $\begin{array}{l}\text { Yes } \\
\text { n (\%) }\end{array}$ \\
\hline \multirow{6}{*}{$\begin{array}{l}\text { Have you encountered any of the } \\
\text { following medical emergencies? }\end{array}$} & Fainting attack $(n=370)$ & $95(25.7)$ \\
\hline & Foreign body inhalation $(n=370)$ & $138(37.3)$ \\
\hline & Epileptic attack $(\mathrm{n}=370)$ & $96(26.0)$ \\
\hline & Uncontrolled bleeding $(n=370)$ & $92(24.9)$ \\
\hline & Chest pain $(n=370)$ & $99(26.8)$ \\
\hline & Shortness of breath $(n=370)$ & $130(35.1)$ \\
\hline \multirow{4}{*}{$\begin{array}{l}\text { Type of training received (by those who } \\
\text { have received training) }\end{array}$} & Simulation $(n=370)$ & $130(35.1)$ \\
\hline & Seminars $(n=369)$ & $177(48.0)$ \\
\hline & Videotapes $(n=370)$ & $150(40.5)$ \\
\hline & Slides and PowerPoint $(n=369)$ & $167(45.3)$ \\
\hline \multirow{5}{*}{$\begin{array}{l}\text { Medical emergency procedure } \\
\text { encountered during your practice }\end{array}$} & Venepuncture $(\mathrm{n}=369)$ & $47(12.7)$ \\
\hline & Endotracheal intubation $(n=370)$ & $40(10.8)$ \\
\hline & Pulse oximetry $(n=370)$ & $58(15.7)$ \\
\hline & Automated external defibrillation $(n=370)$ & $37(10.0)$ \\
\hline & Cardiopulmonary resuscitation $(\mathrm{n}=370)$ & $45(12.2)$ \\
\hline
\end{tabular}

Table 3 shows the Chi-squared associations between having attended a ME workshop and various ME skills and knowledge, as well as experience of MEs and their management. Attending a ME workshop had a statistically significant association with the self-reported ability to provide artificial respiration, CPR, and intramuscular, subcutaneous and intravenous injections, having received CPR training, as well as encountering MEs (foreign body inhalation, chest pain, shortness of breath), and procedures (CPR, automated external defibrillation, venepuncture, intubation, pulse oximetry) while in practice.

Table 3. Associations of attending a ME workshop

\begin{tabular}{|c|c|c|c|c|c|c|c|}
\hline \multirow[t]{2}{*}{ Variable } & & & \multicolumn{2}{|c|}{$\begin{array}{l}\text { Participants that had attended a } \\
\text { ME workshop }\end{array}$} & \multirow{2}{*}{$\begin{array}{l}\text { Total } \\
\text { (n) }\end{array}$} & \multirow[t]{2}{*}{$\chi^{2}$} & \multirow{2}{*}{$\mathrm{p}$} \\
\hline & & & No (n) & Yes (n) & & & \\
\hline \multirow{12}{*}{$\begin{array}{l}\text { Do you have the } \\
\text { following skills? }\end{array}$} & \multirow{2}{*}{ Artificial respiration } & No & 133 & 77 & 210 & \multirow{2}{*}{6.67} & \multirow{2}{*}{$.01 *$} \\
\hline & & Yes & 79 & 81 & 160 & & \\
\hline & \multirow{2}{*}{$\begin{array}{l}\text { Give an intramuscular } \\
\text { injection }\end{array}$} & No & 144 & 56 & 200 & \multirow{2}{*}{37.85} & \multirow{2}{*}{$\leq .001^{*}$} \\
\hline & & Yes & 67 & 102 & 169 & & \\
\hline & \multirow{2}{*}{$\begin{array}{l}\text { Give a subcutaneous } \\
\text { injection }\end{array}$} & No & 161 & 89 & 250 & \multirow{2}{*}{15.01} & \multirow{2}{*}{$\leq .001^{*}$} \\
\hline & & Yes & 51 & 69 & 120 & & \\
\hline & \multirow{2}{*}{$\begin{array}{l}\text { Give an intravenous } \\
\text { injection }\end{array}$} & No & 178 & 106 & 284 & \multirow{2}{*}{13.52} & \multirow{2}{*}{$\leq .001 *$} \\
\hline & & Yes & 34 & 52 & 86 & & \\
\hline & \multirow{2}{*}{ Check the carotid pulse } & No & 40 & 24 & 64 & \multirow{2}{*}{.62} & \multirow{2}{*}{.43} \\
\hline & & Yes & 172 & 134 & 306 & & \\
\hline & \multirow{2}{*}{$\begin{array}{l}\text { Perform Heimlich } \\
\text { manoeuvre }\end{array}$} & No & 114 & 78 & 192 & \multirow{2}{*}{.54} & \multirow{2}{*}{.46} \\
\hline & & Yes & 98 & 80 & 178 & & \\
\hline
\end{tabular}




\begin{tabular}{|c|c|c|c|c|c|c|c|}
\hline \multirow{6}{*}{ Cardiopulmonary resuscitation } & \multirow{2}{*}{$\begin{array}{l}\text { Do you have any knowledge about } \\
\text { CPR? }\end{array}$} & No & 22 & 8 & 30 & \multirow{2}{*}{2.76} & \multirow{2}{*}{.10} \\
\hline & & Yes & 190 & 150 & 340 & & \\
\hline & \multirow{2}{*}{$\begin{array}{l}\text { Do you receive any type of CPR } \\
\text { training? }\end{array}$} & No & 132 & 47 & 179 & \multirow{2}{*}{37.04} & \multirow{2}{*}{$\leq .001^{*}$} \\
\hline & & Yes & 80 & 111 & 191 & & \\
\hline & \multirow{2}{*}{ Can you perform CPR? } & No & 126 & 54 & 180 & \multirow{2}{*}{22.12} & \multirow{2}{*}{$\leq .001 *$} \\
\hline & & Yes & 86 & 104 & 190 & & \\
\hline \multirow{2}{*}{ Medical emergency training } & \multirow{2}{*}{$\begin{array}{l}\text { Are you willing to undergo any } \\
\text { training on handling medical } \\
\text { emergencies in future? }\end{array}$} & No & 41 & 20 & 61 & \multirow{2}{*}{2.47} & \multirow{2}{*}{.12} \\
\hline & & Yes & 171 & 138 & 309 & & \\
\hline \multirow{6}{*}{$\begin{array}{l}\text { Do you have the knowledge about } \\
\text { emergency drugs and their routes of } \\
\text { administration? }\end{array}$} & \multirow{2}{*}{ Oxygen } & No & 55 & 35 & 90 & \multirow{2}{*}{.52} & \multirow{2}{*}{.47} \\
\hline & & Yes & 157 & 123 & 280 & & \\
\hline & \multirow{2}{*}{ Adrenaline } & No & 60 & 53 & 113 & \multirow{2}{*}{.94} & \multirow{2}{*}{.33} \\
\hline & & Yes & 152 & 105 & 257 & & \\
\hline & \multirow{2}{*}{$\begin{array}{l}\text { Are you aware of the common drugs } \\
\text { used in dentistry that can precipitate } \\
\text { an allergic reaction? }\end{array}$} & No & 50 & 26 & 76 & \multirow[b]{2}{*}{2.40} & \multirow[b]{2}{*}{.12} \\
\hline & & Yes & 162 & 132 & 294 & & \\
\hline \multirow{12}{*}{$\begin{array}{l}\text { Have you encountered any of the } \\
\text { following medical emergencies? }\end{array}$} & \multirow{2}{*}{ Fainting attack } & No & 160 & 115 & 275 & \multirow{2}{*}{.22} & 64 \\
\hline & & Yes & 52 & 43 & 95 & & \\
\hline & Fomion bodv inholotion & No & 151 & 81 & 232 & 1450 & $<00$ \\
\hline & 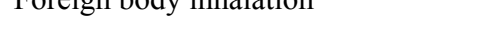 & Yes & 61 & 77 & 138 & 14.00 & $=.001$ \\
\hline & Enilontio attolt & No & 162 & 112 & 274 & 117 & 28 \\
\hline & LPHepie dila & Yes & 50 & 46 & 96 & 1.17 & .20 \\
\hline & & No & 169 & 109 & 278 & 5.02 & $.03 *$ \\
\hline & 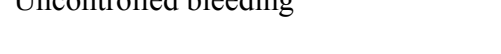 & Yes & 43 & 49 & 92 & & \\
\hline & Chest nain & No & 174 & 97 & 271 & 1872 & \\
\hline & Cnest pain & Yes & 38 & 61 & 99 & $18 . / 2$ & $\leq .00$ \\
\hline & Shortnecs of hrenth & No & 156 & 84 & 240 & 1568 & $<00$ \\
\hline & SHortuess or oreatin & Yes & 56 & 74 & 130 & 15.00 & $=.001$ \\
\hline & Venonuncture & No & 195 & 127 & 322 & 001 & $002 *$ \\
\hline & vericpurctirc & Yes & 17 & 30 & 47 & 9.01 & .005 \\
\hline & Intuhation & No & 200 & 129 & 329 & 1383 & \\
\hline & intuodionin & Yes & 12 & 28 & 40 & $10.0 J$ & -.001 \\
\hline Have you encountered any of the & Dylco ovimetwe & No & 192 & 120 & 312 & 1255 & \\
\hline procedures during your practice? & 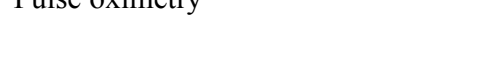 & Yes & 20 & 38 & 58 & 15.JJ & -.001 \\
\hline & Automated external defibrillation & No & 204 & 129 & 333 & 1980 & $<001 *$ \\
\hline & & Yes & 8 & 29 & 37 & & \\
\hline & monory rocucsitation & No & 203 & 122 & 325 & 27,77 & \\
\hline & - & Yes & 9 & 36 & 45 & 21.72 & .00 \\
\hline
\end{tabular}

Note. $\chi^{2}=$ Chi squared, $*=$ statistically significant.

The associations of gender with ME skills, knowledge and experiences were then examined. Gender was significantly associated with encountering venepuncture $\chi^{2}(1, n=369)=8.01, p=.005$, intubation $\chi^{2}(1, n=369)=$ $5.21 \mathrm{p}=.02$, automated external defibrillation $\chi^{2}(1, \mathrm{n}=370)=4.83, \mathrm{p}=.03$, and cardiopulmonary resuscitation $\chi^{2}(1$, $\mathrm{n}=370)=6.02, \mathrm{p}=.01$, in practice. Gender was also associated with the ability to give a subcutaneous injection $\chi^{2}(1$, 
$\mathrm{n}=370)=4.43, \mathrm{p}=.04$, to perform the Heimlich manoeuvre $\chi^{2}(1, \mathrm{n}=370)=6.25, \mathrm{p}=.01$, to have knowledge about $\operatorname{CPR} \chi^{2}(1, \mathrm{n}=370)=4.67, \mathrm{p}=.03$, and attending a workshop on handling MEs $\chi^{2}(1, \mathrm{n}=370)=3.9, \mathrm{p}=.05$. There was no significant association of gender and the self-perceived ability to: deliver artificial respiration, IM and IV injections, checking the carotid pulse, performance of CPR, attendance at previous CPR training, willingness to participate in future ME training, knowledge of oxygen, adrenaline and drugs which may precipitate an allergic reaction, encountering any of the specified MEs, or encountering pulse oximetry during practice.

\section{Discussion}

This study explored the perceptions of final year dental students at JUST and JU regarding their education and preparedness to manage MEs within a dental office. Overall the student cohort reported sub-optimal levels of ME knowledge and skill. Less than half of the respondents reported possessing emergency medical skills such as providing artificial respiration, administering injections by various routes, and performing the Heimlich manoeuvre. In comparison, over $80 \%$ reported knowing how to check the carotid pulse. Moreover, only $51.4 \%$ reported that they could perform CPR. This is comparable to a previous project conducted in Saudi Arabia, which reported only $45 \%$ of dentists felt competent to perform CPR (Alhamad et al., 2015). Other studies have likewise reported the majority of dentists felt they are unable or unprepared to provide CPR, BLS or first aid in an emergency (Arsati et al., 2010; Stafuzza et al., 2014; Varma et al., 2015).

Approximately half of the present cohort reported that they had done some CPR training. This compares to figures reported in other studies; 56\% of dental interns in Southern India had BLS training (Elanchezhiyan et al., 2013), a report from Nigeria documented that $58 \%$ final year students had received medical emergency training (Ehigiator, Ehizele, \& Ugbodaga, 2014), an Indian study reported that three quarters of dental interns had received some ME training (Abraham \& Afradh, 2016), and approximately six in 10 dentists in a Brazilian study had undergone CPR training (Arsati et al., 2010). It is noteworthy that the majority of dentists and dental students feel that they require more training in BLS and MEs and have a positive attitude to learning these skills (Abraham \& Afradh, 2016; Mwita et al., 2017; Somaraj et al., 2017). This is reflected in the present cohort where $83.5 \%$ of participants were willing to do further ME training.

At least a quarter of the cohort had been exposed to one of the MEs included in the questionnaire. The literature reports varying amounts of exposure to MEs by students and dentists. It has been reported that one to two thirds of dental interns have encountered a ME (Elanchezhiyan et al., 2013; Leelavathi et al., 2016), with other reports stating that over a third of dental practitioners have encountered at least $1 \mathrm{ME}$ over the previous few years (Joshi \& Acharya, 2016; Mwita et al., 2017). Additional studies have reported higher incidence levels (Broadbent \& Thomson, 2001; Müller et al., 2008); however, it is difficult to compare studies as various reporting timeframes have been used.

The present study has demonstrated a statistically significant association between previous attendance at a ME workshop and the self-perceived ability to perform artificial respiration and CPR as well as the various skills, such as giving IM injections, that may be required in an emergency medical situation. Previous studies have likewise shown that BLS training increases levels of BLS confidence, skills and knowledge (Ibnerasa \& de Garve, 2016; Sharma \& Attar, 2012).

However, self-perceived confidence in a skill and being able to perform the skill effectively may be two disparate entities, as demonstrated in a study of French dental students where more students felt competent to perform CPR than were able to when examined practically (Laurent et al., 2009). The over-estimation of CPR competencies has also been reported for other healthcare students (Grześkowiak, 2006), and may be influenced by social desirability (Van de Mortel, 2008). Thus, for future studies, it may be important to include practical examination of skills to allow a better understanding of the interaction of educational interventions on skill acquisition.

Although structured BLS and ME training should be an integral component of dental undergraduate curricula (Sharma \& Attar, 2012), it is also important to consider the value of repeated BLS / ME training throughout undergraduate and postgraduate periods. Resuscitation skills have been shown to decline from six weeks post training, with the greatest decreases occurring between six and twelve months (Yang et al., 2012). A survey of general dentists and final year students demonstrated that students had a higher level of knowledge of the management of medically unwell patients than practitioners (Ghapanchi, Shahidi, Kamali, \& Zamani, 2016), and Akbari et al (2015) reported that more professional dental experience was associated with lower ME management awareness (Akbari, Raeesi, Ebrahimipour, \& Ramezanzadeh, 2015). These studies suggest that it is not enough to have a single exposure to ME management education and training, but rather the importance of ongoing, repeated theory and practical sessions throughout the life of a dental student and practitioner. 
A limitation of this study is the self-report nature of the questionnaire due to the possibility of a social desirability response bias. That is, participants responding in a way that is perceived to be appropriate within their social and/or professional environment. One may propose that this could be particularly true of health professionals when answering items which reveal their knowledge or competencies. A further limitation may be a non-response bias, where those who didn't respond to the questionnaire may have answered items differently than those who did respond. Furthermore, the use of a novel, non-validated survey limits generalisability. To advance understanding in this area, it would be beneficial for the questionnaire used in this study to undergo examination for validity and reliability. It is also recommended that further studies in this area examine the effects of educational interventions upon questionnaire findings and skill acquisition.

\section{Conclusion}

Although the occurrence of MEs within dental practice is relatively infrequent, it is vital for dental practitioners to have the knowledge, confidence, and competence to be able to identify and manage a ME in practice. This study demonstrates that the participating final year dental students have less than optimal levels of self-perceived knowledge and competency with regards to the management of medical emergencies. However the majority are willing to attend future training in this area. This indicates that the student cohort view training in medical emergency management as an important inclusion in dental education. Along with the importance of competence in this area, it is proposed that medical emergency management should be a mandatory component when planning dental undergraduate curricula.

\section{Acknowledgements}

The authors would like to thank the Deanship of Research (JUST) for funding this study, as well as colleagues at JUST and JU for facilitating access to students for data collection.

\section{Competing Interests Statement}

The authors declare that they have no competing interests regarding the publication of the paper.

\section{References}

Abraham, S., \& Afradh, K. M. (2016). Knowledge about Medical Emergencies among Interns in Dental Colleges in Chennai. e-MIDAS Journal, 3(2), 8-11.

Akbari, N., Raeesi, V., Ebrahimipour, S., \& Ramezanzadeh, K. (2015). Dentists' Awareness about Management of Medical Emergencies in Dental Offices Birjand-2014. Scholars Journal of Dental Sciences, 2(4), 285-289.

Alhamad, M., Alnahwi, T., Alshayeb, H., Alzayer, A., Aldawood, O., Almarzouq, A., \& Nazir, M. A. (2015). Medical emergencies encountered in dental clinics: A study from the Eastern Province of Saudi Arabia. Journal of Family and Community Medicine, 22(3), 175. https://doi.org/10.4103/2230-8229.163038

Anders, P. L., Comeau, R. L., Hatton, M., \& Neiders, M. E. (2010). The nature and frequency of medical emergencies among patients in a dental school setting. Journal of Dental Education, 74(4), 392-396.

Arsati, F., Montalli, V. Â., Flório, F. M., Ramacciato, J. C., da Cunha, F. L., Cecanho, R., . . Motta, R. H. L. (2010). Brazilian dentists' attitudes about medical emergencies during dental treatment. Journal of Dental Education, 74(6), 661-666.

Atherton, G., McCaul, J., Williams, S., Atherton, G., McCaul, J., \& Williams, S. (1999). Medical emergencies in general dental practice in Great Britain. Part 1: Their prevalence over a 10-year period. British Dental Journal, 186(2). https://doi.org/10.1038/sj.bdj.4800023a

Broadbent, J., \& Thomson, W. (2001). The readiness of New Zealand general dental practitioners for medical emergencies. New Zealand Dental Journal, 97, 82-86.

Cooper, S., Johnston, E., \& Priscott, D. (2007). Immediate life support (ILS) training: Impact in a primary care setting? Resuscitation, 72(1), 92-99. https://doi.org/10.1016/j.resuscitation.2006.06.004

Čuković - Bagić, I., Hrvatin, S., Jeličić, J., Negovetić Vranić, D., Kujundžić Tiljak, M., Pezo, H., \& Marks, L. (2017). General dentists' awareness of how to cope with medical emergencies in paediatric dental patients. International Dental Journal. https://doi.org/10.1111/idj.12286

Ehigiator, O., Ehizele, A., \& Ugbodaga, P. (2014). Assessment of a group of Nigerian dental students' education on medical emergencies. Annals of Medical and Health Sciences Research, 4(2), 248-252. https://doi.org/10.4103/2141-9248.129052

Elanchezhiyan, S., Elavarasu, S., Vennila, K., Renukadevi, R., Mahabob, M. N., Sentilkumar, B., \& Raja, S. (2013). 
Awareness of dental office medical emergencies among dental interns in southern India: an analytical study. Journal of Dental Education, 77(3), 364-369.

Feck, A. (2012). Preparing for medical emergencies in the dental office. Retrieved August 29, 2017, from http://www.dentaleconomics.com/content/dam/de/print-articles/Volume\%20102/Issue\%2012/decourse.pdf

Ghapanchi, J., Shahidi, S. P., Kamali, F., \& Zamani, L. (2016). Knowledge and Attitude of General Dentists and Last-year Students Regarding the Management of Medically Compromised Patients in Shiraz, Iran. British Journal of Medicine and Medical Research, 11(2), 1-6. https://doi.org/10.9734/BJMMR/2016/19576

Grześkowiak, M. (2006). The effects of teaching basic cardiopulmonary resuscitation-a comparison between first and sixth year medical students. Resuscitation, 68(3), 391-397. https://doi.org/10.1016/j.resuscitation.2005.07.017

Ibnerasa, S., \& de Garve, W. (2016). Perceptions of dental students on introduction of simulation-based BLS teaching in their course. AMEE MedEdPublish, 5(2), 48. https://doi.org/10.15694/mep.2016.000076 Jevon, P. (2012). Updated guidance on medical emergencies and resuscitation in the dental practice. British Dental Journal, 212(1), 41-43. https://doi.org/10.1038/sj.bdj.2011.1101

Joshi, S., \& Acharya, S. (2016). Medical Emergencies in Dental Practice-A Nepalese study. Orthodontic Journal of Nepal, 5(2), 33-37. https://doi.org/10.3126/ojn.v5i2.15223

Laurent, F., Augustin, P., Nabet, C., Ackers, S., Zamaroczy, D., \& Maman, L. (2009). Managing a cardiac arrest: evaluation of final-year predoctoral dental students. Journal of Dental Education, 73(2), 211-217.

Leelavathi, L., Reddy, V. C., Elizabeth, C. P., \& Priyadarshni, I. (2016). Experience, awareness, and perceptions about medical emergencies among dental interns of Chennai city, India. Journal of Indian Association of Public Health Dentistry, 14(4), 440. https://doi.org/10.4103/2319-5932.195831

Little, J. W., Miller, C., \& Rhodus, N. L. (2018). Dental Management of the Medically Compromised Patient (9th ed.). Missouri, USA: Elsevier Health Sciences.

Müller, M., Hänsel, M., Stehr, S., Weber, S., \& Koch, T. (2008). A state-wide survey of medical emergency management in dental practices: incidence of emergencies and training experience. Emergency Medicine Journal, 25(5), 296-300. https://doi.org/10.1136/emj.2007.052936

Mwita, S. F., Machibya, F. M., \& Nyerembe, S. A. (2017). Evaluation of knowledge, experience and preparedness on management of medical emergencies among dental practitioners in Dar es Salaam, Tanzania. International Journal of Contemporary Dentistry, 6, 1-6.

National Centre for Chronic Disease Prevention and Health Promotion. (2011). Healthy aging: Helping people to live long and productive lives and enjoy a good quality of life. Retrieved August 15, 2017, from http://www.aarp.org/content/dam/aarp/livable-communities/learn/health/Healthy-Aging-Helping-People-toLive-Long-and-Productive-Lives-and-Enjoy-a-Good-Quality-of-Life-2011-AARP.pdf

Passel, J. S., \& Cohn, D. (2008). US population projections: 2005-2050. Retrieved August 15, 2017, from http://www.pewhispanic.org/files/reports/85.pdf

Prince, M. J., Wu, F., Guo, Y., Robledo, L. M. G., O'Donnell, M., Sullivan, R., \& Yusuf, S. (2015). The burden of disease in older people and implications for health policy and practice. The Lancet, 385(9967), 549-562. https://doi.org/10.1016/S0140-6736(14)61347-7

Radfar, L., \& Suresh, L. (2007). Medical profile of a dental school patient population. Journal of Dental Education, 71(5), 682-686.

Resuscitation Council (UK). (2015). Consensus paper on out-of-hospital cardiac arrest in England. Retrieved August 23, 2017, from https://www.bhf.org.uk/-/media/files/publications/ohca-consensus-paper.pdf.

Roudi-Fahimi, F., \& Kent, M. M. (2007). Challenges and opportunities: The population of the Middle East and North Africa. Population Bulletin, 62(2), 3-6.

Sharma, R., \& Attar, N. R. (2012). Adult basic life support (BLS) awareness and knowledge among medical and dental interns completing internship from deemed university. Nitte University Journal of Health Science, 2(3), $6-13$.

Somaraj, V., Shenoy, R. P., Panchmal, G. S., Jodalli, P. S., Sonde, L., \& Karkal, R. (2017). Knowledge, attitude and anxiety pertaining to basic life support and medical emergencies among dental interns in Mangalore City, India. World Journal of Emergency Medicine, 8(2), 131-135. 
https://doi.org/10.5847/wjem.j.1920-8642.2017.02.009

Stafuzza, T. C., Carrara, C. F. C., Oliveira, F. V., Santos, C. F., \& Oliveira, T. M. (2014). Evaluation of the dentists' knowledge on medical urgency and emergency. Brazilian Oral Research, 28(1), 1-5. https://doi.org/10.1590/10.1590/1807-3107BOR-2014.vol28.0029

Van de Mortel, T. F. (2008). Faking it: social desirability response bias in self-report research. Australian Journal of Advanced Nursing, 25(4), 40-48.

Varma, L. S. C., Pratap, K., Padma, T. M., Kalyan, V. S., \& Vineela, P. (2015). Evaluation of preparedness for medical emergencies among dental practitioners in Khammam town: A cross-sectional study. Journal of Indian Association of Public Health Dentistry, 13(4), 422. https://doi.org/10.4103/2319-5932.171178

World Health Organization. (2015). World report on ageing and health. Retrieved September 1, 2017, from http://apps.who.int/iris/bitstream/10665/186463/1/9789240694811_eng.pdf?ua=1

Yang, C.-W., Yen, Z.-S., McGowan, J. E., Chen, H. C., Chiang, W.-C., Mancini, M. E., . . Ma, M. H.-M. (2012). A systematic review of retention of adult advanced life support knowledge and skills in healthcare providers. Resuscitation, 83(9), 1055-1060. https://doi.org/10.1016/j.resuscitation.2012.02.027

\section{Copyrights}

Copyright for this article is retained by the author(s), with first publication rights granted to the journal.

This is an open-access article distributed under the terms and conditions of the Creative Commons Attribution license (http://creativecommons.org/licenses/by/4.0/). 